\title{
RETRACTED ARTICLE: Prediction of condensate-to-gas ratio by using stochastic particle swarm optimization and neural network
}

\author{
Mohammad Ali Ahmadi - Seyed Reza Shadizadeh • \\ Mohammad Ebadi · Reza Khalighi Sheshdeh
}

Received: 13 December 2011/Accepted: 22 May 2012/Published online: 28 June 2012

(C) Springer-Verlag London Limited 2012

This article has been retracted at the request of the author,

following concerns over the paper's integrity.

M. A. Ahmadi ( $\square)$

Department of Petroleum Engineering,

Ahwaz Faculty of Petroleum Engineering,

Petroleum University of Technology,

P.O.BOX: 63431, Kut Abdollah, Ahwaz, Iran

e-mail: ahmadi6776@yahoo.com

S. R. Shadizadeh

Department of Petroleum Engineering,

Abadan Faculty of Petroleum Engineering,

Petroleum University of Technology, Abadan, Iran

M. Ebadi

Department of Petroleum Engineering, Science and Research

Branch, Islamic Azad University, Tehran, Iran

R. Khalighi Sheshdeh

Department of Gas Engineering, Ahwaz Faculty of Petroleum

Engineering, Petroleum University of Technology, Ahwaz, Iran 